See Article page e289.

\section{Commentary: Red cell damage after cardiopulmonary bypass: The dark side of exosomes}

\author{
Victor A. Ferraris, MD, PhD
}

Enthusiasm for exosomes as possible therapeutic targets was stimulated by the award of a Nobel Prize in Medicine to 3 investigators for their discovery of the machinery regulating cellular vesicle transport (https:/www.nobelprize.org/prizes/ medicine/2013/summary/). These Nobel laureates were recognized for identifying a set of genes that are required for microvesicle (ie, exosome) creation and transport, defining how exosomes delivered their cargoes to the right places, and discovering the cellular and extracellular machinery that controls exosome release of chemical messengers.

Exosomes are among the multiple extracellular vesicles that can be shed by cellular processes and participate in membrane trafficking. Membrane trafficking is the process by which proteins and other macromolecules move within a cell or are released into the extracellular space. Membrane trafficking can employ extracellular vesicles produced by the cell membrane and these vesicles can act as a transport intermediary for various intracellular and extracellular processes.

The descriptions of exosomes are broad and a bit nebulous. Descriptions include small membrane-covered vesicles shed in the maturation process of red blood cells (RBCs), but also include vesicles that develop into endosomes (intracellular vesicles), particles with specific physiological roles, and even the vesicles found in the sediment after ultracentrifugation of fluids such as cell culture conditioned media, blood plasma, urine, breast milk, or saliva. An important distinction relates to how exosomes are produced. Endosomes are formed by invagination within a cell to

\footnotetext{
From the Division of Cardiothoracic Surgery, Department of Surgery, University of Kentucky and Lexington VA Medical Center, Lexington, Ky.

Disclosures: The author reported no conflicts of interest.

The Journal policy requires editors and reviewers to disclose conflicts of interest and to decline handling or reviewing manuscripts for which they may have a conflict of interest. The editors and reviewers of this article have no conflicts of interest.

Received for publication Nov 25, 2020; revisions received Nov 25, 2020; accepted for publication Nov 30, 2020; available ahead of print Dec 4, 2020.

Address for reprints: Victor A. Ferraris, MD, PhD, Division of Cardiothoracic Surgery, Department of Surgery, University of Kentucky and Lexington VA Medical Center, A301 Kentucky Clinic, 740 S Limestone Ave, Lexington, KY 405360284 (E-mail: ferraris@uky.edu).

J Thorac Cardiovasc Surg 2022;164:e309-10

0022-5223/\$0.00

Published by Elsevier Inc. on behalf of The American Association for Thoracic Surgery

https://doi.org/10.1016/j.jtcvs.2020.11.138
}
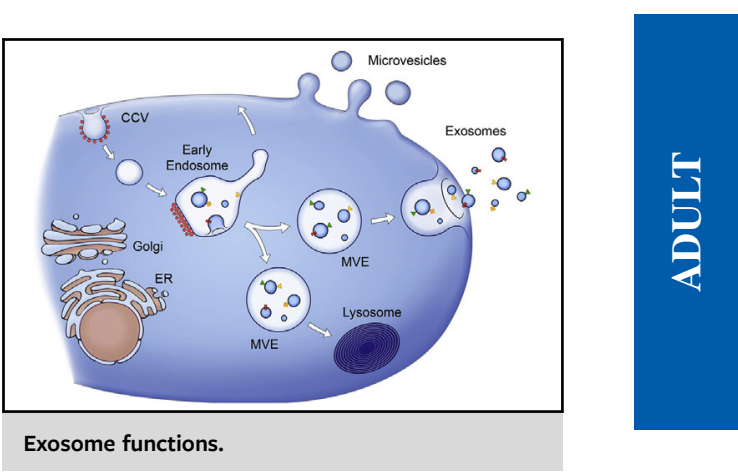

create an intracellular vesicle called an endosome, or an endocytic vesicle. Endosomes differ from exosomes that are formed by a process of membrane budding (called exocytosis). ${ }^{1}$ There is good evidence that endogenous vesicles shed by cells function in interorgan communication. ${ }^{2}$ As a result, exosomes are being developed as therapeutic and diagnostic agents in multiple disease models. ${ }^{3-5}$

Pat and colleagues ${ }^{6}$ present an intriguing examination of the potential progression of acute kidney injury (AKI) following cardiopulmonary bypass (CPB). They found increased levels of circulating RBC exosomes in the peripheral blood of patients who developed AKI. What is novel about the research by Pat and colleagues ${ }^{6}$ is that exosomes, from RBCs in this case, may serve a destructive purpose in certain circumstances. The authors showed that plasma RBC exosomes are generated during and shortly after CPB. In a rat model of CPB, the authors showed that injection of these exosomes into the bloodstream induced AKI and associated chronic renal damage. These interesting findings raise the possibility that $\mathrm{CPB}$-generated exosomes may modulate kidney injury after CPB. These findings also signal a note of caution about the enthusiasm for medical therapeutic uses of exosomes as delivery vehicles for drugs and other therapies, because the exact actions of these extracellular vesicles may not be completely understood in all cases. 
As is typical, the review process involving this article resulted in a moderation of the authors' conclusions. The authors initially suggested that there is a cause-and-effect relationship between exosome generation and AKI after operation. It is not at all clear how the influence of CPB may generate exosomes and alter renal function. Further, it is very uncertain whether $\mathrm{RBC}$ exosomes have the destructive effects on certain organ systems suggested by the authors in their rat model. Their results are intriguing and suggest that these cause-and-effect relationships may exist, but there is clearly much more work that needs to be done before this can be solidified. Future work needs to identify methods to reduce toxic exosomes if they exist and to develop modifications to $\mathrm{CPB}$ that might reduce the risk of exosome formation. This type of work is important because of the substantial prevalence of beneficial effects attributed to exosomes. A simple trait assigned to exosomes may not be correct. There are other examples of apparent characteristics of exosomes altering gene expression that were believed to be beneficial but were found to be more complex and possibly harmful. ${ }^{7}$ It could well be that exosomes are not perfect therapeutic agents in all situations. Perhaps more importantly, if exosomes prove to have toxic renal effects after $\mathrm{CPB}$, this offers a new and potentially exciting target to reduce renal injury risk after CPB. Clearly, more work needs to be done, but the potential spectrum of future studies involving exosomes is intriguing.

\section{References}

1. Pegtel DM, Gould SJ. Exosomes. Annu Rev Biochem. 2019;88:487-514.

2. Verweij FJ, Revenu C, Arras G, Dingli F, Loew D, Pegtel DM, et al. Live tracking of inter-organ communication by endogenous exosomes in vivo. Dev Cell. 2019; 48:573-89.

3. Ramayanti O, Verkuijlen S, Novianti P, Scheepbouwer C, Misovic B, KoppersLalic D, et al. Vesicle-bound EBV-BART13-3p miRNA in circulation distinguishes nasopharyngeal from other head and neck cancer and asymptomatic EBV-infections. Int J Cancer. 2019;144:2555-66.

4. Zhang S, Chuah SJ, Lai RC, Hui JHP, Lim SK, Toh WS. MSC exosomes mediate cartilage repair by enhancing proliferation, attenuating apoptosis and modulating immune reactivity. Biomaterials. 2018;156:16-27.

5. Ferraris VA. Enhanced exosomes and spinal cord ischemia: excitement and a Nobel Prize but more to come. J Thorac Cardiovasc Surg. 2019;157:518-9.

6. Pat B, Oh J-Y, Juncos JXM, Powell PC, Collawn JF, Patel RP, et al. Red blood cell exosome hemoglobin content increases after cardiopulmonary bypass and mediates acute kidney injury in an animal model. J Thorac Cardiovasc Surg. 2022; 164:e289-308.

7. Ferraris VA. Reply: a "simple" way for enhanced exosomes to alter gene expression: simple but wrong-complex but right. J Thorac Cardiovasc Surg. 2019;158:e88-9.

\section{Commentary: The morbidity of "perfect surgery"-moving the lab bench closer to the operating table}

\author{
Torsten Doenst, $\mathrm{MD}, \mathrm{PhD}$, and \\ Michael Schwarzer, $\mathrm{PhD}$
}

What constitutes the difference in outcome between 2 patients with the same cardiac pathology if one patient dies but surgery (and postoperative care) was perfect? The answer is clear: comorbidities! Although this answer may provide some

\footnotetext{
From the Department of Cardiothoracic Surgery, Friedrich-Schiller-University Jena, University Hospital, Jena, Germany.

Disclosures: The authors reported no conflicts of interest.

The Journal policy requires editors and reviewers to disclose conflicts of interest and to decline handling or reviewing manuscripts for which they may have a conflict of interest. The editors and reviewers of this article have no conflicts of interest.

Received for publication Dec 2, 2020; revisions received Dec 2, 2020; accepted for publication Dec 2, 2020; available ahead of print Dec 8, 2020

Address for reprints: Torsten Doenst, MD, PhD, Department of Cardiothoracic Surgery, University of Jena, Am Klinikum 1, 07747 Jena, Germany (E-mail: doenst@med.uni-jena.de).

J Thorac Cardiovasc Surg 2022;164:e310-1

0022-5223/\$36.00

Copyright (c) 2020 by The American Association for Thoracic Surgery

https://doi.org/10.1016/j.jtcvs.2020.12.009
}

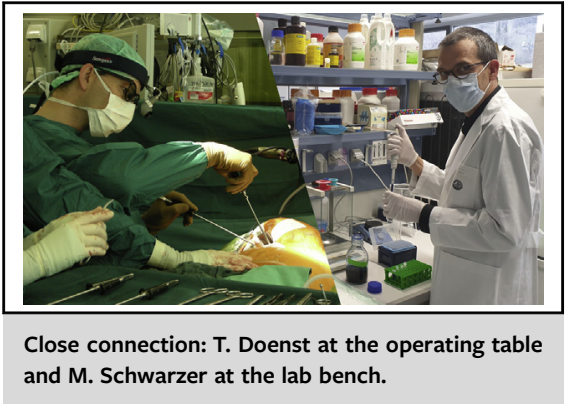

CENTRAL MESSAGE

Morbidity and mortality may

occur despite perfect surgery.

Molecular and cellular mecha-

nisms gain increasing importance

for improving outcomes. The lab

bench moves closer to the

operating table. 